\title{
PENGARUH FREKUENSI MENYIKAT GIGI TERHADAP DEBRIS INDEKS PADA SISWA KELAS V DI SD KARTIKA XXI-4 KECAMATAN PAAL DUA KOTA MANADO
}

\author{
Ni Made Yuliana, S.Kp.G, M.Kes. ${ }^{1}$, Jeineke E. Ratuela,S.SiT, MDSc ${ }^{2}$ \\ Poltekkes Kesehatan Kemenkes Manado ${ }^{12}$ \\ Emaiul : ${ }^{1}$ nimadeyuliana0604@gmail.com
}

\begin{abstract}
Dental and oral health is very important to always be maintained, one way to prevent dental and oral health problems can be done by brushing teeth. A good frequency and time of brushing teeth is 3 times a day in the morning after breakfast, in the afternoon after lunch and at night before going to bed. The purpose of this study was to determine the effect of tooth brushing frequency on the debris index in fifth grade students at SD Kartika XXI-4, Paal Dua District, Manado City. This type of research is analytic with a cross sectional study approach using the total sampling method. The frequency of brushing teeth was measured using a check-list sheet to find out how many times the respondent brushed his teeth in a day, and the debris index was examined using the debris index examination format. The research results obtained were then processed using the analysis of the Kendall's tau correlations test. The results of the analysis using the kendall's tau correlation test obtained a value of -0.798 with a strong correlation strength with a $p$ value of 0.000 smaller than the value of $=0.05$ so that there is a significant correlation value between the variable frequency of brushing teeth and the debris index variable with a negative correlation direction (- ) which means that the greater the frequency of brushing the teeth, the smaller the value of the debris index. So it can be concluded that there is an effect of tooth brushing frequency on the debris index.
\end{abstract}

Keywords: tooth brushing frequency, index debris

\begin{abstract}
ABSTRAK
Kesehatan gigi dan mulutsangatpentinguntukselaludijaga, salah satu cara mencegah terjadinya masalah kesehatan gigi dan mulut dapat dilakukan dengan menyikat gigi. Frekuensidan waktumenyikatgigi yang baikyaitu 3 kali seharipagisetelahmakanpagi, siang setelah makan siang dan malam sebelum tidur. Tujuan penelitian ini untuk mengetahui pengaruh frekuensi menyikat gigi terhadap debris indeks pada siswakelas V di SD Kartika XXI-4 Kecamatan Paal Dua Kota Manado. Jenis penelitian ini bersifat analitik dengan pendekatan cross sectional study dengan menggunakan metode total sampling. Frekuensi menyikat gigi diukur menggunakan lembar check-list untuk mengetahui berapa kali responden menyikat gigi dalam sehari, dan debris indeks dilakukan pemeriksaan dengan menggunakan format pemeriksaan debris indeks. Hasil penelitian yang diperoleh kemudian diolah menggunakan analisis uji correlations kendall's tau. Hasil analisis menggunakan uji correlations kendall's tau didapatkan nilai sebesar -0,798 dengan kekuatan korelasi kuat dengan nilai $p$ sebesar 0,000 lebih kecil dari nilai $\alpha=0,05$ sehingga terdapat nilai korelasi yang bermakna antara variabel frekuensi menyikat gigi dengan variabel debris indeks dengan arah korelasi negatif (-) yang berarti semakin besar nilai frekuensi menyikat gigi maka semakin kecil nilai debris indeks. Sehingga dapat disimpulkan bahwa ada pengaruh frekuensi menyikat gigi terhadap debris indeks.
\end{abstract}

Kata kunci :frekuensi menyikat gigi, debris indeks 


\section{PENDAHULUAN}

Mulut merupakan organ pencernaan yang pertama bertugas dalam proses pencernaan makanan. Fungsi utama mulut adalah untuk menghancurkan makanan sehingga ukurannya cukup kecil untuk dapat ditelan kedalam perut. Mulut dapat menghaluskan makanan karena di dalam mulut terdapat gigi dan lidah. Gigi berfungsi menghancurkan makanan, dan lidah berfungsi untuk membolak-balikkan makanan sehingga semua makanan dihancurkan secara merata (Hidayat dkk, 2016).

Kesehatan gigi dan mulut sangat penting untuk selalu dijaga. Namun di Indonesia masih banyak ditemukan masalah kesehatan, khususnya masalah kesehatan gigi dan mulut yang jumlah penderitanya masih sangat tinggi. Pada hasil Riset Kesehatan Dasar (RISKESDAS) tahun 2013 jumlah penduduk Indonesia yang mengalami masalah kesehatan gigi dan mulut sebanyak 25,9 persen, dan untuk kelompok umur 10-14 tahun sebanyak 25,2 persen. Di Sulawesi Utara masalah kesehatan gigi dan mulut cukup tinggi sebanyak 31,6 persen (Kemenkes, RI. 2013). Penduduk yang mengalami masalah kesehatan gigi dan mulut di Indonesia menurut Riset Kesehatan Dasar (RISKESDAS) tahun 2018 mengalami peningkatan 19,4 persen pada tahun 2018 yaitu sebanyak 45,3 persen dan untuk kelompok umur 10-14 tahun mengalami peningkatan 16,2 persen yaitu sebanyak 41,4 persen. Masalah kesehatan gigi dan mulut di Sulawesi Utara juga mengalami peningkatan 23,9 persen yaitu sebanyak 55,5 persen(Kemenkes, RI. 2018). Jika terus dibiarkan dan tidakditangani segera maka masalah kesehatan gigi dan mulut di Indonesia akanterusmeningkat.

Kebersihan gigi dan mulut merupakan bagian terpenting ketika seseorang menjaga kesehatan giginya (Margareta, S. 2012). Kebersihan gigi dan mulut adalah keadaan dimana permukaan gigi terbebas dari sisa-sisa makanan yang mengandung bakteri yang dapat merusak gigi. Untuk mencegah terjadinya masalah kesehatan gigi dan mulut dapat dilakukan dengan menyikat gigi. Menyikat gigi adalah cara yang umum dianjurkan untuk membersihkan deposit lunak pada permukaan gigi dan gusi dan merupakan tindakan preventif dalam menuju keberhasilan dan kesehatan rongga mulut yang optimal (Putri dkk, 2010).

Frekuensi menyikat gigi yang baik yaitu 3 kali sehari pagi setelah makan pagi, siang setelah makan siang dan malam sebelum tidur (Hermawan, R. 2010). Riset Kesehatan Dasar (RISKESDAS) tahun 2018 di Indonesia untuk kegiatan menyikat gigi setiap hari pada kelompok umur 10-14 tahun yaitu sebanyak 96,5 persen, tetapi hanya 2,1 persen yang menyikat gigi dengan benar (Kemenkes, RI. 2018). Penelitian Katty, J (2014) tentang hubungan frekuensi menyikat gigi dengan debris indeks pada siswa kelas
V dan VI di SD Negeri 8 Manado sebanyak 57 responden. Didapatkan bahwa frekuensi menyikat gigi satu kali sehari sebanyak 16 responden $(28,1 \%)$, dua kali sehari sebanyak 34 responden $(59,7 \%)$, tiga kali sehari sebanyak 7 responden $(12,2 \%)$. Dengan hasil penelitian bahwa terdapat hubungan yang signifikan antara hubungan frekuensi menyikat gigi dengan debris indeks pada siswa kelas V dan VI di SD Negeri 8 Manado. Survey awal Sekolah Dasar Kartika XXI-4 Kecamatan Paal Dua Kota Manado diperoleh debris indeks (DI) kriteria baik 1 orang, kriteria sedang 5 orang dan kriteria buruk 4 orang. Dengan Debris Indeks (DI) rata-rata sebanyak 1,9 pada kategori buruk. Hal ini menunjukkan bahwa kriteria debris indeks melebihi standar yang di tetapkan oleh Greene dan Vermillion, yaitu 0-0,6 pada kategori baik.

Saat dilakukan wawancara pada siswa-siswi mengenai masalah kesehatan gigi, mereka kadang mengeluhkan masalah sakit gigi yang disebabkan karena kerusakan pada gigi atau gigi berlubang. Untuk mencegah kerusakan gigi dan bau mulut bisa dilakukan dengan menyikat gigi menurut Hermawan, R., (2010). Dan wawancara pada siswasiswi mengenai frekuensi dan waktu menyikat gigi diketahui bahwa siswa-siswi menyikat gigi dua kali sehari tetapi hanya pada waktu mandi pagi dan sore hari. Sedangkan menurut Hidayat dkk (2016) waktu terbaik untuk menyikat gigi adalah setelah makan dan sebelum tidur. Hasil dari wawancara mengenai frekuensi dan waktu menyikat gigi dengan pemeriksaan debris indeks tidak sesuai dengan yang diharapakan.

Berdasarkan uraian pada latar belakang maka peneliti merasa tertarik untuk melakukan penelitian tentang pengaruh frekuensi menyikat gigi terhadap debris indeks pada siswa kelas V di SD Kartika XXI4 Kecamatan Paal Dua Kota Manado.

\section{A. RumusanMasalah}

Berdasarkan latar belakang masalah, dapat dirumuskan sebagai berikut "Apakah ada pengaruh frekuensi menyikat gigi terhadap debris indeks pada siswa kelas V di SD Kartika XXI-4 Kecamatan Paal Dua Kota Manado?"

\section{B. TujuanPenelitian}

Untuk mengetahui pengaruh frekuensi menyikat gigi terhadap debris indeks pada siswa kelas V di SD Kartika XXI-4 Kecamatan Paal Dua Kota Manado. 


\section{Vol. 16 No.2 Mei - Agustus 2021}

\section{ManfaatPenelitian}

1. ManfaatTeoritis

Penelitian ini diharapkan dapat memberikan masukan dan manfaat bagi perkembangan ilmu pengetahuan dibidang kesehatan gigi dan mulut yang berkaitan dengan pengaruh frekuensi menyikat gigi terhadap debris indeks pada siswa kelas V di SD Kartika XXI-4 Kecamatan Paal Dua Kota Manado.

2. ManfaatPraktis

a. Untuk Sekolah

Untuk meningkatkan pengetahuan siswa kelas V di SD Kartika XXI-4 Kecamatan Paal Dua Kota Manado tentang frekuensi menyikat gigi dengan debris indeks.

b. Untuk Akademik

Sebagai bahan refrensi bagi institusi dalam perpustakaan Politeknik Kesehatan Kemenkes Manado serta sebagai bahan kajian untuk penelitian selanjutnya.

c. Bagi Penulis

Dapat menambah wawasan dan pengetahuan secara langsung dalam melakukan penelitian serta dapat mengaplikasikan ilmu yang diproleh.

\section{Hipotesis}

Ada pengaruh frekuensi menyikat gigi terhadap debris indeks pada siswa kelas V di SD Kartika XXI4 Kecamatan Paal Dua Kota Manado.

\section{METODE PENELITIAN}

Jenis penelitian ini bersifat analitik dengan pendekatan cross sectionalstudy, dimana data yang menyangkut variable bebas dan variable terikat akan dikumpul dalam waktu yang bersamaan (Saryono, 2011).

Waktu dan Tempatpenelitian

Waktu Penelitian dilaksanakan pada minggu ke 3 bulan Mei 2019 selama 3 hari. Tempat penelitian di SD Kartika XXI-4 Kecamatan Paal Dua Kota Manado. VariabelPenelitian Variabel Bebas : Frekuensi Menyikat Gigi Variabel Terikat : Debris Indeks. DefinisiOperasional Frekuensi dan waktu menyikat gigi sebaiknya 3 kali sehari, setiap kali sesudah makan dan sebelum tidur.Frekuensi dan waktu menyikat gigi diukur dengan menggunakan lembar check-list untuk mengetahui seberapa banyak orang menyikat gigi dalam satu hari. Waktu menyikat gigi yang tepat yaitu pagi setelahmakan pagi, siang setelah makan siang dan malam setelah makan malam atau sebelum tidur malam, dan waktu menyikat gigi yang salah yaitu pagi saat mandi pagi atau sebelum makan pagi, siang sebelum makan siang, sore saat mandi sore,dan malam sebelum makanmalam. Frekuensi dan waktu menyikat gigidibagimenjaditigakriteriayaitubaik, sedang dan buruk. Kriteriabaikdiberinilai 3 jikarespondenmenyikatgigidenganfrekuensi 3 kali sehari pada waktu yang tepat, kriteriasedangdiberinilai 2 jikarespondenmenyikatgigidenganfrekuensi 2 kali sehari pada waktu yang tepatatau 3 kali seharitetapihanyadua kali pada waktu yang tepat dan satu kali pada waktu yang salah, dan kriteriaburukdiberinilai jikarespondenmenyikatgigi 1 kali sehari, 2 kali sehariatau 3 kali seharitetapi pada waktu yang salah skala ordinal.

1. Debris indeks dilakukan pemeriksaan dengan menggunakan format pemeriksaan debris indeks. Cara menghitung nilai debris indeks yaitu jumlah seluruh skor segmen dibagi dengan jumlah segmen yang dipriksa. Dengan kriteria penilaian baik jika nilainya antara $(0-0,6)$ diberi nilai 3 , sedang jika nilainya antara $(0,7-1,8)$ diberi nilai 2 dan buruk jika nilainya antara $(1,9$ $3,0)$ diberi nilai 1 skala ordinal.

Populasi Dan Sampel. Populasi dalam penelitian ini adalah seluruh siswa kelas V di SD Kartika XXI4 Kecamatan Paal Dua Kota Manado yang berjumlah 48 siswa. Sampel yang akan digunakan siswa kelas V di SD Kartika XXI-4 Kecamatan Paal Dua Kota Manado yang berjumlah 48 siswa. Teknik pengambilan sampel pada penelitian ini menggunakan total sampling.

A. InstrumenPenelitian

1. Lembar check-list, dan format pemeriksaan debris indeks.

2. Alat diagnosa set (kaca mulut, sonde, pinset, dan excavator), nierbeken, alat tulis, handuk bersih.

3. Bahan kapas, alkohol $70 \%$, cotton pellet, larutan disklosing, air mineral, dan air bersih untuk mencuci alat.

\section{Teknik Pengumpulan Data}

1. Data Primer

Data yang diproleh dari responden dengan cara wawancara, dan observasi atau pemeriksaan Debris Indeks (DI).

2. Data Sekunder 
Data yang diperoleh dari pihak sekolah mengenai jumlah siswa kelas V di SD Kartika XXI-4 Kecamatan Paal Dua Kota Manado.

\section{Analisis Data}

Hasil penelitian yang diproleh kemudian diolah secara statistik dengan menggunakan softwere computer SPSS dengan analisis uji correlations kendall's tau untuk mengetahui ada atau tidaknya pengaruh frekuensi menyikat gigi terhadap debris indeks pada siswa kelas V SD Kartika XXI-4 Kecamatan Paal Dua Kota Manado.

\section{HASIL PENELITIAN}

1. Analisis Data

a. Distribusi Responden Menurut Jenis Kelamin

Distribusi responden menurut jenis kelamin pada siswa kelas V di SD Kartika XXI-4 Kecamatan Paal Dua Kota Manado, dapatdilihat pada tabelberikut :

Tabel 3. Distribusi Responden Menurut Jenis Kelamin

\begin{tabular}{lll}
\hline JenisKelamin & $\mathrm{n}$ & $\%$ \\
\hline Laki-laki & 22 & 45,8 \\
Perempuan & 26 & 54,2 \\
\hline Jumlah & 48 & 100 \\
\hline
\end{tabular}

Data pada tabel 3 distribusi responden menurut jenis kelamin, menunjukkan bahwa responden pada jenis kelamin perempuan sebanyak 26 responden $(54,2 \%)$, sedangkan pada jenis kelamin laki-laki sebanyak 22 responden (45,8\%).Distribusi Responden Menurut Golongan Umur Distribusi responden menurut golonganumur pada siswa kelas V di SD Kartika XXI-4 Kecamatan Paal Dua Kota Manado, dapatdilihat pada tabelberikut :

Tabel 4. Distribusi Responden Menurut GolonganUmur

\begin{tabular}{lll}
\hline Umur & $\mathrm{n}$ & $\%$ \\
\hline 9 Tahun & 5 & 10,4 \\
10 Tahun & 23 & 48,0 \\
11 Tahun & 16 & 33,3 \\
12 Tahun & 4 & 8,3 \\
\hline Jumlah & 48 & 100
\end{tabular}

Data pada tabel 4 distribusirespondenmenurutgolonganumurmenu njukkanbahwapada golonganumur 10 tahunsebanyak 23 responden $(48,0 \%)$, umur 11 tahunsebanyak 16 responden $(33,3 \%)$, umur9 tahunsebanyak 5 responden $(10,4 \%)$, dan umur 12 tahunsebanyak 4 responden $(8,3 \%)$.

b. DistribusiRespondenMenurutFrekuensiMe nyikat Gigi

Distribusi responden menurut frekuensimenyikatgigi padasiswa kelas V di SD Kartika XXI-4 Kecamatan Paal Dua Kota Manado, dapatdilihat pada tabelberikut :

Tabel 5. Distribusi Responden Menurut FrekuensiMenyikat Gigi

\begin{tabular}{lll}
\hline $\begin{array}{l}\text { FrekuensiMenyikat } \\
\text { Gigi }\end{array}$ & $\mathrm{n}$ & $\%$ \\
\hline 3 Kali Sehari & 14 & 29,2 \\
2 Kali Sehari & 30 & 62,5 \\
1 Kali Sehari & 4 & 8,3 \\
\hline Jumlah & 48 & 100 \\
\hline
\end{tabular}

Data pada tabel 5 distribusi responden menurutfrekuensimenykatgigi, menunjukkan bahwa pada frekuensimenyikatgigi 2 kali seharisebanyak 30 responden $(62,5 \%)$, frekuensimenyikatgigi 3 kali seharisebanyak 14 responden $(29,2 \%)$, dan frekuensimenyikatgigi 1 kali seharisebanyak 4 responden $(8,3 \%)$.

c. DistribusiRespondenMenurutFrekuensi dan Waktu Menyikat Gigi yang Tepat Distribusirespondenmenurutfrekuensi dan waktumenyikatgigi yang tepatpada siswa kelas V di SD Kartika XXI-4 Kecamatan Paal Dua Kota Manado, dapatdilihat pada tabelberikut :

Tabel 6. Distribusi Responden Menurut Frekuensidan Waktu Menyikat Gigi yang Tepat

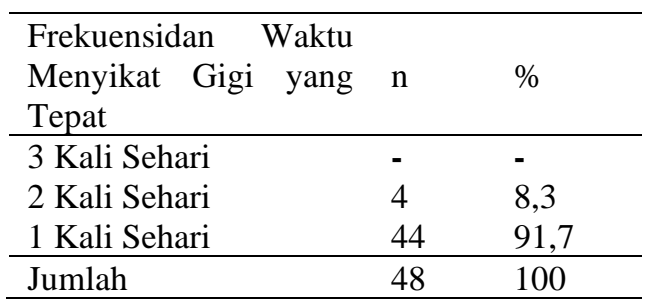

Data pada tabel 6 berdasarkantabeldistribusi responden menurutfrekuensi dan waktumenyikatgigi yang tepat, menunjukkan bahwa frekuensi dan waktumenyikatgigiyang 


\section{Vol. 16 No.2 Mei - Agustus 2021}

tepat paling banyakterdapat pada frekuensi dan waktumenyikatgigi 1 kali sehariyaitu 44 responden (91,7\%), frekuensi dan waktumenyikatgigi 2 kali seharisebanyak 4 responden $(8,3 \%)$, sedangkanuntukfrekuensi dan waktumenyikatgigi 3 kali seharitidakada.

d. Distribusi Responden Menurut Kriteria Debris Indeks

Distribusi responden menurut kriteria debris indeks pada siswa kelas V di SD Kartika XXI-4 Kecamatan Paal Dua Kota Manado, dapatdilihat pada tabelberikut :

Tabel 7. Distribusi Responden Menurut Kriteria Debris Indeks

\begin{tabular}{lll}
\hline Kriteria & $\mathrm{n}$ & $\%$ \\
Debris Indeks & - & -
\end{tabular}

Tabel 8. Tabel Silang Frekuensidan Waktu Menyikat Gigi yang TepatDengan Debris Indeks

\begin{tabular}{lll} 
Sedang & 42 & 87,5 \\
Buruk & 6 & 12,5 \\
\hline Jumlah & 48 & 100 \\
\hline
\end{tabular}

Data pada tabel 7 berdasarkantabeldistribusi responden menurutkriteria debris indeksmenunjukkanbahwakriteriasedangsebany ak42 responden $(87,5 \%)$, kriteriaburuksebanyak 6 responden (12,5\%), dan untukkriteriabaiktidakada.

e. Tabel Silang Frekuensi dan Waktu Menyikat Gigi Dengan Debris Indeks

Berdasarkantabelsilangfrekuensimenyikatgigide ngan debris indekspada siswa kelas V di SD Kartika XXI-4 Kecamatan Paal Dua Kota Manado, dapatdilihat pada tabelberikut :

\begin{tabular}{|c|c|c|c|c|c|c|c|c|c|}
\hline \multirow{3}{*}{$\begin{array}{l}\text { Frekuensi dan } \\
\text { WaktuMenyik } \\
\text { at Gigi }\end{array}$} & \multicolumn{7}{|c|}{ Debris Indeks } & \multicolumn{2}{|c|}{ TotalPersentasi } \\
\hline & \multirow{2}{*}{$\begin{array}{l}\text { Bai } \\
\mathrm{k} \\
\mathrm{n}\end{array}$} & \multicolumn{3}{|c|}{ Sedang } & \multicolumn{3}{|c|}{ Buruk } & & \\
\hline & & $\%$ & $\mathrm{n}$ & $\%$ & $\mathrm{n}$ & $\%$ & & & \\
\hline $\begin{array}{l}\text { Baik (3 Kali } \\
\text { Sehari) }\end{array}$ & - & - & - & - & - & - & & - & - \\
\hline $\begin{array}{l}\text { Sedang (2 Kali } \\
\text { Sehari) }\end{array}$ & - & - & 4 & 8,3 & - & - & & 4 & 8,3 \\
\hline $\begin{array}{l}\text { Buruk (1 Kali } \\
\text { Sehari) }\end{array}$ & - & - & 38 & 79,2 & 6 & 12,5 & 44 & 91,7 & \\
\hline Total & & & 42 & 87,5 & 6 & 12,5 & 48 & 100 & \\
\hline
\end{tabular}


Data pada tabel 8 menurut distribusi table silang frekuensi menyikat gigi dengan debris indeks menunjukkan bahwa frekuensi menyikat gigi 1 kali sehari sebanyak 44 responden $(91,7 \%)$ dengankriteria debris indeks sedang sebanyak 38 responden $(79,2 \%)$, criteria buruk sebanyak 6 respon den $(12,5 \%)$, dan criteria baik tidak ada. Fekuensi menyikat gigi 2 kali sehari sebanyak 4 responden $(8,3 \%)$ dengan kriteria debris indeks sedang sebanyak 4 responden

$(8,3 \%)$, kriteria buruk dan kriteria baik tidak ada. Sedangkan untuk frekuensi menyikat gigi 3 kali sehari tidak ada. Analisis Data Menggunakan Uji Correlations Kendall's Tau. Berdasarkan analisis data menggunakan uji correlations kendall'stau mengenai frekuensi menyikat gigi dengan debris indeks pada siswa kelas V di SD Kartika XXI-4 Kecamatan Paal Dua Kota Manado, dapat dilihat pada table berikut :

Tabel 9. Analisis Data Menggunakan Uji Correlations Kendall's Tau

\begin{tabular}{lll}
\hline & Debris Indeks & \\
\cline { 2 - 3 } Frekuensi & $r$ & $-0,798$ \\
Menyikat Gigi & $p$ & 0,000 \\
& $n$ & 48 \\
\hline
\end{tabular}

Data pada tabel 9 hasil analisis menggunakan uji correlations kendall's tau didapatkan nilai sebesar ,798 dengan kekuatan korelasi kuat yaitu antara nilai 0,60-0,799 dengan nila ip sebesar 0,000 lebih kecil dari nilai $\alpha=0,05$ sehingga terdapat nilai korelasi yang bermaknakan atau signifikan antara variable frekuensi menyikat gigi dengan debris indeks, dengan arah korelasi negatif (-) yang berarti semakin besar nilai frekuensi menyikat gigi maka semakin kecil nilai debris indeks.

\section{Pembahasan}

Kebersihan gigi dan muluta dalah keadaan dimana permukaan gigi terbebas dari sisasisa makanan yang mengandung bakteri yang dapat merusak gigi (Putri dkk, 2010). Kebersihan gigi dan mulut merupakan bagian terpenting Ketika seseorang menjaga Kesehatan giginya (Margareta, S. 2012).

Debris adalah lapisan lunak yang melekat pada permukaan gigi yang terdiri dari plak, material alba, dan food debris (Putri dkk, 2010). Plak adalah lapisan tipis yang melekat pada permukaan gigi (Sariningsih, E. 2014). Plak mengandung organisme patogen yang terbentuk setiap hari pada permukaan gigi yang kejadiannya berhubungan dengan konsumsi makanan (Bahar, 2011).Material alba adalah suatu deposit lunak, berwarna kuning atau putih keabu-abuan yang melekat pada permukaan gigi, restorasi, kalkulus dan gingiva. Food debris (debris makanan) mengandung bakteri, tetapi berbeda dari plak dan material alba, debris ini lebih mudah dibersihkan (Putri dkk, 2010). Untuk mencegah terjadinya masalah kesehata ngigi dan mulutdapatdilakukandenganmenyikatgigi. Menyikatgigiadalahcara yang umum dianjurkan untuk membersihkan deposit lunak pada permukaangigi dan gusi dan merupakan tindakanp reventif dalam menuju keberhasilan dan kesehatan rongga mulut yang optimal (Putri dkk, 2010).Sikat gigi merupakan salah satu alatfisio terapi oral yang digunakan secara luas untuk membersihkan gigi dan mulut dari sisasisamakanan dan debris yang melekat pada permukaangigi (Putri dkk, 2010). Waktu terbaik untuk menyikat gigi adalah setelah makan dan sebelum tidur yaitu pada pagi hari setelah makan pagi, siang setelah makan siang, dan malam sebelum tidur. Menyikat gigi setelah makan bertujuan mengangkat sisa-sisa makanan yang menempel dipermukaan ataupun disela-sela gigi dan gusi (Hidayat dkk, 2016). Berdasarkan tabel silang frekuensi menyikat gigi dengan debris indeks menunjukkan bahwa frekuensi menyikat gigi 1 kali sehari sebanyak 44 responden $(91,7 \%)$ dengan kriteria debris indeks sedang sebanyak 38 responden $(79,2 \%)$, kriteria buruk sebanyak 6 responden $(12,5 \%)$, dan kriteria baik tidak ada. Frekuensi menyikat gigi 2 kali sehari 
Vol. 16 No.2 Mei - Agustus 2021

sebanyak 4 responden $(8,3 \%)$ dengan kriteria debris indeks sedang sebanyak 4 responden $(8,3 \%)$, kriteriaburuk dan kriteria baik tidak ada. Sedangkan untuk frekuensi menyikat gigi 3 kali sehari tidak ada. Kriteria debris indeks sedang dan buruk pada responden disebabkan karena frekuensi menyikat giginya sudah baik tetapi waktu menyikat gigi masih kurang tepat sehingga hasil yang didapatkan dalam pemeriksaan debris indeks hanya terdapat pada kriteria sedang dan kriteria buruk. Untuk memperoleh kebersihan gigi dan mulut yang optimal harus memperhatikan frekuensi, waktu dan teknik menyikat gigi yang baik dan benar.Menurut Sriyono, 2005 buruknya kebersihan gigi dan mulut bisa disebabkan karena kurangnya pengetahuan tentang menyikat gigi yang baik dan benar dan kurang memperhatikan waktu menyikat gigi yang tepat. Hasil analisis menggunakan uji correlations kendall's tau didapatkan nilai sebesar -0,798 dengan kekuatan korelasi kuat yaitu antara nilai 0,60 0,799 dengan nilaip sebesar 0,000 lebih kecil dari nilai $\alpha=0,05$ sehingga terdapat nilai korelasi yang bermakna atau signifikan antara variable frekuensi menyikat gigi dengan debris indeks, dengan arah korelasi negatif (-) yang berarti semakin besar nilai frekuensi menyikat gigi maka semakin kecil nilai debris indeks.

Hasil penelitian ini sejalan dengan penelitian yang dilakukan oleh Safitri, R., 2015 tentang hubungan tingkat pengetahuan frekwensi menyikat gigi terhadap kebersihan gigi dan mulut pada siswa kelas IV SDN 28 Mataram, bahwa terdapat hubungan tingkat pengetahuan frekwensi menyikat gigi terhadap kebersihan gigi dan mulut.

\section{KESIMPULAN}

Berdasarkan hasi penelitian yang telah dilakukan pada siswa kelas V di SD Kartika XXI-4 Kecamatan Paal Dua Kota Manado menggunakan analisis uji correlations kendall's tau didapatkan nilai sebesar - 0,798 dengan kekuatan korelasi kuat yaitu antara nilai 0,60-0,799 dengan nila ip sebesar 0,000 lebih kecil dari nilai $\alpha=0,05$ sehingga terdapat nilai korelasi yang bermaknakan atau signifikan antara variable frekuensi menyikat gigi dengan debris indeks sehingga dapat disimpulkan bahwa ada pengaruh frekuensi menyikat gigi terhadap debris indeks.

\section{DAFTAR PUSTAKA}

Ali. (2010). PengertianSiswaMenurut Para Ahli. www.duniapelajar.com.Diakses pada Tanggal 15 April 2019

Bahar,

A.

(2011).

PradigmaBaruPencegahanKaries

Gigi.

Lembar

PenerbitFakultasEkonomi UI. Jakarta

Hermawan, R. (2010). Menyehatkan Daerah Mulut. BukuBiru. Jakarta

Hidayat, R., \&Tandiari, A. (2016). Kesehatan Gigi dan MulutApa yang Sebaiknya Anda Tahu ?.Yogyakarta : Andi

Katty, $\mathrm{J}$.

(2014).

HubunganFrekuensiMenyikat Gigi dengan Debris Indeks pada Siswa Kelas $V$ dan VI di SD Negeri 8 Manado. JurusanKeperawatan Gigi. Politeknik Kesehatan Manado

Kementrian Kesehatan, RI. (2013). Riset Kesehatan Dasar 2013. Badan Penelitian dan Pengembangan Kesehatan RI. Jakarta

Kementrian Kesehatan, RI. (2018). Riset Kesehatan Dasar 2018. Badan Penelitian dan Pengembangan Kesehatan RI. Jakarta

Layuk

$\mathrm{S}$.

(2017).

PedomanPenulisanKaryaTulisIlmiah

Skripsi Kementerian Kesehatan RI Politeknik Kesehatan Kemenkes. Manado

Margareta, S. (2012). 101 Tips \&TerapiAlami agar Gigi putih\&Sehat. Pustaka Cerdas. Yogyakarta

Priyatno, D. (2017). Panduan PraktisOlah Data Menggunakan SPSS. ANDI. Yogyakarta

Putri, M.H., Herijulianti, F., \&Nurjanah, N. (2010). 
IlmuPencegahanPenyakitJaringanKe ras dan JaringanPendukung Gigi. EGC. Jakarta

Sariningsih, E. (2014). Gigi Busuk dan Poket Periodontal SebagaiFokusInfeksi. PT Alex Media KomputindoKelompok Gramedia. Jakarta

Saryono. (2011). MetodologiPenelitian Kesehatan. Mitra Cendikia Press. Jogjakarta

Safitri, R. (2015). Hubungan Tingkat PengetahuanFrekwensiMenyikat Gigi TerhadapKebersihan Gigi dan Mulut Pada Siswa Kelas IV SDN 28 Mataram. Akademi Kesehatan Gigi Karya Adi HusadaMataram. Diakses pada Tanggal 05 Juni 2019

Sriyono, N.W. (2005). IlmuKedokteran Gigi Pencegahan.

MedikaFakultasKedokteran UGM, Yogyakarta

Sugiyono. (2009). StatistikauntukPenelitian. CV ALFABETA. Bandung

Umaternate, A. (2017). HubunganPengetahuantentang Cara Menggosok Gigi dengan Debris Indeks pada Siswa Kelas IV SD GMIM 23 Manado.JurusanKeperawatan Gigi. Politeknik Kesehatan Manado 